\title{
Elementos para uma releitura clínica da noção de narcisismo a partir das relações entre anorexia e melancolia
}

\section{Elements for a clinical reinterpretation of the concept of narcissism from the relationship between anorexia and melancholy}

\section{Elementos para una reinterpretación clínica del concepto de narcisismo de la relación entre la anorexia y la melancolía}

\section{Cristina Moreira Marcos*}

Pontifícia Universidade Católica - PUC-Minas, Belo Horizonte, Minas Gerais, Brasil

\section{Renata Damiano Riguini**}

Pontifícia Universidade Católica - PUC-Minas, Belo Horizonte, Minas Gerais, Brasil

\section{RESUMO}

Em 1914, Freud afirma que o narcisismo é uma operação essencial para que o sujeito constitua um eu e um corpo. A experiência clínica evidencia as dificuldades e os obstáculos para que esta necessária ação psíquica se conclua satisfatoriamente na esquizofrenia, na paranoia, na melancolia ou na histeria. Com Freud, compreendemos que a constituição do corpo como próprio é algo a ser alcançado. Já está presente na metapsicologia freudiana a ideia sobre a qual o sujeito tem com seu corpo uma relação de exterioridade, e que ele precisa apropriar-se deste corpo. A anorexia e a melancolia evidenciam as dificuldades desta operação. Com Lacan, o problema da anorexia não se deixa reduzir a uma fragilidade narcísicoimaginária. A partir daí, a dimensão imaginária somente deve ser considerada em relação com o Outro e com o gozo. Um caso clínico nos permite verificar que a anorexia pode funcionar como uma suplência imaginária em um caso de melancolia.

Palavras-chave: narcisismo, anorexia, melancolia.

\section{ABSTRACT}

In 1914, Freud says that the narcissism is an essential operation for which the subject constitutes an ego and a body. The clinical experience highlights the difficulties and obstacles for this necessary psychic action become satisfactorily concluded in schizophrenia, paranoia, melancholy or in hysteria. With Freud, we understand that the constitution of the own body as something to be achieved. Is already present in Freudian metapsychology the idea according to which the subject has with his body a relationship of exteriority and that he needs to take ownership of his body. The anorexia and the melancholy show the difficulties of this operation. With Lacan, the problem of anorexia cannot be reduced to a narcissi-imaginary fragility. 
From there, an imaginary dimension should only be considered in relation with the Other and the enjoyment. A clinical case allows us to check that the anorexia can operate as imaginary temping in one case of melancholy.

Keywords: narcissism, anorexia, melancholy.

\section{RESUMEN}

En 1914, dice Freud que el narcisismo es una operación necesaria para que el sujeto constituye un yo and su cuerpo. La experiencia clínica pone de relieve las dificultades y obstáculos para que esta acción psíquica si concluir satisfactoriamente, en la esquizofrenia, la paranoia, la melancolía o en la histeria. Con Freud, entendemos que la constitución del cuerpo proprio es una construcción a ser alcanzada. Ya está presente en la metapsychology freudiano la idea según la cual el sujeto tiene con su cuerpo una relación de exterioridad y que el necesita tomar posesión de este cuerpo. La anorexia y la melancolía evidencian las dificultades de esta operación. Con Lacan, el problema de la anorexia no se reduce a una fragilidad narcisico-imaginario. Desde allí, la dimensión imaginaria solo debe considerarse en relación con el Otro y el gozo. Un caso clínico nos permite comprobar que la anorexia puede funcionar como una suplencia imaginaria en un caso de melancolía.

Palabras-clave: narcisismo, la anorexia, la melancolía.

\section{Elementos para uma releitura clínica da noção de narcisismo a partir das relações entre anorexia e melancolia}

A partir de um caso clínico, destacamos um ponto, a nosso entender, central, para a clínica da anorexia, a saber a ligação entre a anorexia e a melancolia. Buscamos compreender essa relação, apontada por Freud no Rascunho G, através da noção de narcisismo e da relação com o corpo. Nele, Freud afirma:

A neurose nutricional paralela à melancolia é a anorexia. A famosa anorexia nervosa das moças jovens, segundo me parece (depois de cuidadosa observação), é uma melancolia em que a sexualidade não se desenvolveu. A paciente afirma que não se alimenta simplesmente porque não tem nenhum apetite; não há qualquer outro motivo. Perda do apetite - em termos sexuais, perda da libido. (Freud, 1895/1989, p. 283)

Com Freud, compreendemos que a constituição do corpo como próprio é algo a ser alcançado. Já está presente na metapsicologia freudiana a ideia segundo a qual o sujeito tem com seu corpo uma relação de exterioridade e que ele precisa apropriar-se deste corpo. A anorexia evidencia as dificuldades desta operação. Com Lacan, o problema da anorexia não se deixa reduzir a uma fragilidade narcísico-imaginária. A partir daí, a dimensão imaginária somente deve ser considerada em relação com o Outro e com o gozo. Um caso clínico nos permite verificar que a anorexia pode funcionar como uma suplência imaginária em um caso de melancolia. 
Freud (1914/2004) afirma que o narcisismo é uma operação essencial para que o sujeito constitua um eu e um corpo. A experiência clínica evidencia as dificuldades e os obstáculos para que esta necessária ação psíquica se conclua satisfatoriamente, na esquizofrenia, na paranóia, na melancolia ou na histeria. No artigo sobre o narcisismo, Freud assinala que o eu não existe desde o início, mas precisa ser desenvolvido. Esse desenvolvimento depende de uma nova ação psíquica acrescentada ao autoerotismo, que constituirá o narcisismo. Em O eu e o isso (1923/1981), ele dirá que o eu nada mais é do que a projeção de uma superfície corporal.

\section{Alguns apontamentos sobre a noção do narcisismo}

Como Freud chega à noção do narcisismo? É em 1914 que Freud escreve o artigo À guisa de introdução ao narcisismo, mas esta não é a primeira vez que o termo narcisismo aparece no texto freudiano. Freud já o havia empregado em uma reunião da Sociedade Psicanalítica de Viena em 1909. Ele havia declarado que o narcisismo era uma fase intermediária necessária entre o autoerotismo e o amor objetal. Nesse mesmo ano, ele acrescenta uma nota de rodapé sobre a natureza bissexual do indivíduo aos Três ensaios sobre a teoria da sexualidade (Freud, 1905/1989) no qual o termo narcisismo aparece. Em 1910, no livro sobre Leonardo Da Vinci (Freud, 1910/1989), há uma referência consideravelmente extensa ao narcisismo. Freud designa aí o homossexualismo como um determinado tipo de escolha narcísica de objeto, dando relevância à introjeção das figuras parentais na formação da identidade sexual. Ele busca circunscrever as razões que levam um sujeito, no caso Leonardo da Vinci, a uma vida "sentimental homossexual". Freud (1910/1989) aponta que o menino recalca seu amor pela mãe e coloca a si mesmo no lugar de objeto de amor, identificando-se com ela. No mesmo golpe, a criança toma a si própria como ideal, um molde da escolha de seus novos objetos de amor. Torna-se assim, diz Freud, homossexual, e os meninos pelos quais se interessa quando adulto são substitutos de sua própria pessoa infantil. Freud acrescenta "ele escolhe os objetos de seus amores segundo o modo do narcisismo, de acordo com a lenda grega do jovem Narciso a quem nada agradava tanto como sua imagem refletida na água" (Freud, 1910/1989, p. 106).

Encontramos, neste terreno explorado por Freud, a identificação que possibilita a construção do eu. Via um traço comum, a imagem do outro passa a representar o sujeito, assim como acontece nos sonhos. Para Hout (1991), a substituição do sujeito pelo outro e do outro pelo sujeito, coloca na relação intersubjetiva um elemento de representação no sentido do teatro, ou seja, o que o sujeito encarna no outro exibindo-se como desejante. É justamente ele mesmo 
desejado pelo outro. Este é um ponto essencial na obra freudiana para Lacan de onde ele extrai importantes consequências para sua teoria do desejo.

Outras referências se seguem na análise do caso Schreber (Freud, 1911/1989) no qual a escolha narcísica de objeto aparece claramente, passando o narcisismo a ocupar uma posição de destaque na teoria pulsional e em Totem e tabu (Freud, 1913/1989). Neste estudo, Freud generaliza sua tese e faz do narcisismo uma "fase". Para ele, este estágio é o que, em um sujeito em desenvolvimento, unifica suas pulsões sexuais que, até então, agiam de forma autoerótica, tomando seu próprio corpo por objeto de amor antes de investir em uma escolha objetal exterior. Esta universalização do narcisismo é confirmada em Á guisa de introdução ao Narcisismo (Freud, 1914/2004). Hout (1991) destaca que, o que em 1910 e 1911 era a consequência da falha do desejo do outro - no caso, a mãe - torna-se um estágio genérico que possibilita o amor objetal, o desejo pelo outro. Assim, a substituição do sujeito pela imagem do outro parece ser uma condição deste novo arranjo libidinal onde o eu, em construção, está exteriorizado no outro.

Em Totem e tabu (1913/1989), Freud introduz o que chama de "terceira fase", situada entre o autoerotismo e as escolhas objetais.

Nessa fase intermediária, cuja importância a pesquisa tem evidenciado cada vez mais, os instintos sexuais até então isolados já se reuniram num todo único e encontraram também um objeto. Este objeto, porém, não é um objeto externo estranho ao sujeito, mas se trata de seu próprio ego, que se constitui aproximadamente nesta mesma época. Tendo em mente as fixações patológicas desta nova fase, que se tornam observáveis mais tarde, demo-lhes o nome de "narcisismo". O sujeito comporta-se como se estivesse amoroso de si próprio; seus instintos egoístas e seus desejos libidinais ainda não são separáveis pela nossa análise. (Freud, 1913/1989, p. 112)

Freud (1913/1989) afirma que, embora não esteja em condições de descrever com exatidão esta fase na qual as pulsões que até então estavam dissociadas reúnem-se em uma unidade isolada e catexizam - eu como objeto, pode suspeitar que essa organização narcísica nunca é totalmente abandonada. Reconhece aí o protótipo das psicoses e da onipotência de pensamentos nos povos primitivos, nas quais há uma retração da libido dos objetos para o eu. Portanto o narcisismo é apresentado neste texto não unicamente como uma fase intermediária entre o autoerotismo e a escolha objetal, mas também como uma estrutura permanente, que continua a existir. Portanto, quando Freud afirma, no artigo de 1914, que o narcisismo é condição para a formação do eu ele arremeta as elaborações que vinham 
sendo construídas em torno do termo nestes textos anteriormente mencionados.

Pouco mais tarde, em Luto e Melancolia (Freud, 1915/1989) ao tentar esclarecer pontos ainda obscuros sobre o narcisismo, aponta, na melancolia, uma tendência a adoecer decorrente de uma predominância do tipo narcisista de escolha objetal. Freud diz que "se pudéssemos presumir um acordo entre os resultados da observação e o que inferimos, não hesitaríamos em incluir em nossa caracterização da melancolia essa regressão da catexia libidinal para a fase oral ainda narcisista da libido" (Freud, 1915/1989, p. 256).

Toda libido, ou todo desejo, esclarece Hout (1991), é narcísico, assim como não existe desejo sem objeto. O narcisismo é a estruturação escópica que permite existir uma libido de objeto, uma causa para o desejo do sujeito. A pulsão escópica é descrita por Freud em Pulsão e destino das pulsões (Freud, 1915/2004) como apoiada em três fases. Na primeira, o prazer de olhar toma o próprio corpo como objeto, é um estágio eminentemente narcísico. A partir daí, uma pulsão de olhar ativa se desenvolve, abandona o narcisismo e busca um objeto fora, estranho, via identificação, por comparação. A próxima fase é o corpo próprio ser olhado por outrem, um fazer-se olhar que mescla uma passividade - que mantém o objeto narcísico - e uma atividade. Desta forma, o narcisismo primário permanece operante. Podemos ler novamente, aqui, o que Freud concluiu com Leonardo da Vinci: ao olhar o outro o sujeito mostra o desejo que anseia que o outro manifeste por ele. Para Hout, uma das consequências a se retirar desta construção freudiana, é o fato de que o sujeito está representado na imagem do outro. Assim, "o sujeito que vê o outro não se situa no seu lugar, mas sim como representado no e pelo outro", a atividade do outro vai lhe parecer como sua e é somente nesta imagem que ele pode se figurar desejado. A questão da imagem de si passa pelo outro.

Vale ainda observar, que a fixação da libido neste estádio nos aponta duas questões importantes para nosso percurso: a satisfação libidinal implicada neste processo e um complicado dano no plano das identificações. Freud (1914/2004, p. 112) pontua: “Com sempre no campo da libido, o ser humano mostra-se incapaz de renunciar à satisfação já uma vez desfrutada". Para sair do narcisismo, a criança precisa endereçar sua escolha objetal para outro sujeito, cuja identificação é uma etapa preliminar. Nesta passagem, onde o eu deve abandonar a si próprio como objeto para amar, fica um resto. Ele procurará recuperar a perfeição e completude narcísicas da infância na nova forma de um ideal-do-eu. O ideal-do-eu é um substituto, e a manutenção, do narcisismo perdido na infância. Tratase de uma clivagem no eu: por um lado, o eu da realidade e, por outro, o ideal-do-eu, medida pela qual o supereu avaliará, constantemente o eu. 
Para os sujeitos psicóticos, Freud (1914/2004) observa uma predisposição patógena que os manteria fixados na fase do narcisismo primário, para onde retornam, por regressão, quando desencadeada a doença. Mas, como aponta Hout (1991), há um paradoxo nesta configuração. Para o autor, Freud coloca também em destaque, nestes casos, uma catástrofe que afeta o sujeito, inclusive seu corpo, bem como uma rejeição das fantasias e desejos homossexuais, ambos explicitamente relacionados ao narcisismo. Mais uma vez, para além de tomar o eu como objeto - ponto de fixação - o narcisismo é uma estruturação que deve permitir que uma libido de objeto exista fora do eu.

A identificação é importante neste processo, já que é uma etapa preliminar da escolha objetal, ou seja, a primeira forma pela qual o ego escolhe um objeto. Nesta fase, "o ego deseja incoporar a si este objeto e, em conformidade com a fase oral e canibalística do desenvolvimento libidinal em que se acha, deseja fazer isto devorando-o" (Freud, 1915/1989, p.255). Freud vê aí o ponto de origem da recusa alimentar nos casos graves de melancolia. A melancolia apresenta, justamente, um entrincheiramento na incorporação do pai que permanece vivo e indigesto. Ela levanta, mais uma vez, a problematização da constituição do eu e do objeto.

$\mathrm{Na}$ clínica da anorexia, encontramos uma perturbação na identificação narcísica. Há um impasse identificatório do sujeito com sua imagem corporal, com graves consequências para o eu. Isto é evidenciado pela relação problemática e distorcida que a anoréxica estabelece com sua imagem no espelho. Mesmo extremamente emagrecida, a anoréxica se vê gorda, revelando uma relação perturbada com a imagem narcísica.

O narcisismo é uma noção clínica. Trata-se de dar conta da experiência clínica vivida sob transferência. A elaboração deste conceito testemunha o caráter laborioso das tentativas de elaborações teóricas em Freud, sempre em relação com as observações clínicas. Freud nunca propõe uma pura especulação, como é o caso da filosofia. Não por acaso, ele publica em 1913, um artigo O interesse da psicanálise (Freud, 1913a/1989), no qual ele toma o cuidado de precisar que a psicanálise é uma ciência da natureza e não uma ciência do espírito, na medida em que ela parte da experiência e não de uma totalidade ideal como um sistema filosófico. Entretanto o narcisismo freudiano é uma invenção, na medida em que Freud transforma um conceito pré-existente introduzindo-o na psicanálise, sendo exemplar do modo como funciona a teoria psicanalítica. Ele parte sempre de observações clínicas, que busca elaborar e pensar e que modifica outras noções. Com a noção de narcisismo, o corpo como unidade narcísica passa a ser considerado como resultado de uma construção. 


\section{O que Luto e Melancolia ensina sobre a relação entre a anorexia a melancolia}

Podemos dizer que o artigo de 1914 sobre o narcisismo abre as portas para a reflexão sobre o luto e a melancolia e suas condições narcísicas. Em Luto e Melancolia (Freud, 1917/1989) destaca-se a importância não de uma relação objetal, mas da modificação do eu sob o efeito do objeto. Freud explica a melancolia a partir da identificação do eu com o objeto perdido. A libido investida no objeto perdido, ao invés de ser reinvestida em outro objeto, retorna para o eu e estabelece uma identificação do eu com o objeto perdido: "a sombra do objeto cai sobre o eu". O que no luto era uma perda do objeto, na melancolia transforma-se em uma perda do eu.

Freud utiliza o conceito de narcisismo para explicar como o processo melancólico é "auto", nele próprio. Tanto na anorexia quanto na melancolia, há um investimento libidinal excessivo no eu, no corpo, na imagem e uma pobreza de investimentos objetais. Será que podemos pensar que na anorexia, como na melancolia, há uma ruptura da ligação do eu com o objeto e um retorno da libido para seu reservatório original, o eu?

Entretanto, Freud encontra alguns problemas na explicação da melancolia pelo narcisismo. Se o eu está investido narcisicamente como o melancólico teria uma auto-estima tão baixa? E ainda: como esse eu tão carregado de libido narcísica pode atentar contra a própria vida? Isto não seria contrário a uma hipótese de regressão ao narcisismo? A resposta de Freud é que o eu só pode se matar quando ele trata a si mesmo como objeto, dirigindo contra si a hostilidade que visa um objeto.

Pouco antes de Luto e Melancolia (Freud, 1917/1989), Freud havia escrito Pulsões e Destinos da Pulsão (Freud, 1915/2004) no qual ele afirma que os destinos das pulsões podem ser: a transformação em seu contrário, o redirecionamento contra a própria pessoa, o recalque e a sublimação. A autoacusação presente na melancolia pode ser entendida a partir deste destino pulsional, o redirecionamento contra a própria pessoa. O melancólico se autotortura. A autoacusação é considerada, por Freud, um dos traços fundamentais da melancolia. O melancólico se acusa de ser o responsável por suas perdas, pela miséria dos seus familiares e do mundo. Freud interpreta esta acusação que o melancólico dirige a si mesmo como sendo dirigida ao objeto perdido, reintroduzindo assim a dimensão do objeto na autoacusação do eu. Na melancolia, uma parte do eu toma a outra como objeto, julgando-a criticamente. Ele retoma em Luto e Melancolia o que havia desenvolvido no artigo sobre o narcisismo: a existência de um agente crítico que se separa do eu.

Este aspecto também merece uma aproximação entre a anorexia e a melancolia. As noções de ideal do eu e supereu, apenas esboçadas 
em À guisa de introdução ao narcisismo (Freud, 1914/2004) e Luto e Melancolia (Freud, 1917/1989), como agentes críticos que se voltam contra o eu, serão relacionadas em Totem e tabu (1913/1989) à identificação canibalística que consiste em comer e incorporar o pai. Estas instâncias psíquicas são resultado da identificação com o pai morto, agora incorporado.

A hipótese freudiana para explicar a melancolia é a de que a escolha inicial de objeto foi feita sobre uma base narcísica. Por isto, quando o investimento de objeto encontra um obstáculo ele retorna ao narcisismo. O melancólico, que escolheu o objeto de amor via narcisismo, ao perdê-lo volta a esta relação de identificação imaginária, não reinveste a libido em novos objetos e desloca a libido para o eu. O eu incorpora o objeto canibalisticamente. I dentificado ao objeto perdido, o eu passa a ser julgado por um agente especial, como se fosse o próprio objeto. O conflito entre a pessoa amada e o eu transforma-se em uma divisão entre o eu crítico e o eu alterado pela identificação. A identificação narcísica ao objeto se substitui à escolha de objeto de base narcisista. Há uma espécie de regressão da escolha objetal para o narcisismo.

O amor pelo objeto, transformado em identificação narcisista, transmuta-se em ódio contra esse objeto substitutivo. Parte da catexia objetal retrocede para a identificação e outra parte retrocede para o sadismo. Assim podemos compreender a satisfação do eu em se depreciar, pois os ataques do eu se endereçam, na verdade, ao objeto perdido ao qual o eu está identificado.

$\mathrm{Na}$ anorexia, também encontramos uma tensão entre, de um lado, uma instância crítica e, de outro, o eu, o corpo e sua imagem. Nestes casos, o supereu ataca sadicamente o eu, o corpo e sua imagem. Em Freud, o supereu é resultado da identificação primária ao pai. Precisamos lembrar, que a identificação primária, que dá origem ao supereu e ao ideal do eu, é também o que orienta a constituição do eu, do corpo e de sua imagem. Já está presente em Á guisa de introdução ao narcisismo (Freud, 1914/2004) a ideia segundo a qual a constituição do eu se dá em função de um ideal.

Nos casos de anorexia, é frequente a constatação de uma relação com o pai e com a mãe que não favorece a constituição de um ideal, que facilitaria a construção do corpo. É frequente também a tirania e a crueldade dessas instâncias nos sujeitos anoréxicos. Isto acontece na melancolia, na qual o eu, alterado pela identificação com o objeto perdido, ataca sadicamente a outra parte do eu, produzindo uma desordem no narcisismo. Isto parece ser encontrado também na anorexia, na qual o eu e sua imagem são cruelmente depreciados. É a vertente sádica e cruel do supereu que parece se destacar, ao invés da sua face pacificadora. Este aspecto é bastante evidente no caso Joana, discutido mais adiante. Ela se submete às mais duras acusações e punições, atos purgativos, o uso de laxantes, ingestão 
de detergente, shampoo, sabonete. Tudo provoca muita dor mas, segundo ela, compensa.

Freud precisará elaborar o conceito de pulsão de morte e sua manifestação no supereu para que se explique a autoacusação do eu presente na melancolia. O eu identificado com o objeto atrai o ódio do supereu contra ele próprio. A melancolia desvela o sentimento de culpa inconsciente, que é o outro nome do masoquismo moral. Freud descreve a melancolia como um ataque do supereu, revelando-o como pura cultura da pulsão de morte.

$\mathrm{Na}$ segunda tópica freudiana, o supereu ganha relevo. Em O eu e o isso $(1923 / 1981)$, a definição freudiana do supereu está contida nas seguintes afirmações: "O supereu é o herdeiro do complexo de Édipo" e "O supereu é a pura cultura da pulsão de morte". Nelas, temos, por um lado, a face pacificadora, normativa e constituinte do supereu e, por outro, a face cruel e destrutiva, presente na pulsão de morte. Esta última parece se tornar mais evidente na anorexia e na melancolia. Em Mal-estar na Civilização (Freud, 1930/1989), a tese central apresentada é a de que a civilização não só se funda sob a renúncia pulsional mas a exige. Freud destaca, ainda neste texto, que o esforço do supereu alimenta, com a renúncia, a necessidade de renúncia. É um círculo vicioso, quanto mais se aumenta a renúncia mais se reforça a renúncia. Entretanto, podemos pensar que o supereu transforma a renúncia em satisfação, o que é a essência do masoquismo. A pulsão encontra satisfação na renúncia pulsional. $\mathrm{O}$ supereu faz da renúncia à satisfação pulsional, um modo de satisfação pulsional, modo de funcionamento que verificamos na clínica da anorexia.

Ainda é preciso dizer que em Totem e tabu (Freud, 1913/1989), a identificação ao pai morto garante o pacto social entre os irmãos. Entretanto, na melancolia, a perda do objeto gera uma identificação que desfaz o laço com o outro. Este é outro aspecto que encontramos com frequência na anorexia: a ruptura dos laços afetivos e sociais e o isolamento do sujeito. Parecem sujeitos mergulhados no lago de Narciso em uma fascinação pela própria imagem que dispensa o outro. Como nos permite verificar o caso J oana.

\section{0 caso J oana}

Joana é encaminhada ao hospital psiquiátrico aos 20 anos com um quadro de anorexia e episódios frequentes de purgação (vômitos, laxantes e diuréticos), depressiva, apresentando uma grave distorção da imagem corporal e muito debilitada clinicamente a1. Relata uma tentativa de suicídio e solicita internação psiquiátrica para ajudá-la a conter a angústia que a leva a episódios bulímicos. Aos 14 anos, diz que começou a sentir uma tristeza e, aos 17, iniciaram-se os jejuns. 
Afirma que tudo começou quando deixou de ser aceita no grupo de dança da igreja. Relata que se sente gorda e que por isto não come. Queixa-se ainda de dores estomacais, dores de garganta e do mau funcionamento do intestino.

Durante a internação, queixa-se de não poder tomar mais laxantes, pois só ele pode limpar o intestino. Começar a ingerir shampoo e detergente para limpar o organismo. Joana retorna ao hospital reiteradas vezes e durante outras internações relata tentativas de suicídio e alucinações auditivas, após o falecimento do avô dizendo que as vozes the falam para ir ao encontro do avô morto. Afirma que quer morrer para ficar perto do avô e que ele veio buscá-la. Fala também de um relacionamento amoroso que chegou ao fim devido à sua dificuldade em expor seu corpo. Diz que quer ter filhos mas não quer ficar grávida, porque não conseguiria ver a barriga crescendo. Nas últimas internações, as alucinações auditivas desaparecem, a anorexia, o uso de laxantes e os vômitos permanecem mais ou menos intensos.

J oana afirma que não é doente, mas tem um estilo diferente de vida e que precisa ser magra para entrar no mundo da moda. Embora emagrecida, com os cabelos quebradiços, Joana descreve constantemente uma insatisfação com seu corpo e ao se ver no espelho, se vê gorda. Ao ser questionada sobre qual seria o peso ideal, diz que isto não depende dos quilos, mas que enquanto olhar no espelho e se ver gorda não vai comer, "quero ver o osso", "o espelho é meu inimigo". Refere-se a si mesma na terceira pessoa dizendo: "Joana está gorda", "J oana está feia".

É preciso dizer que Lacan não aborda a anorexia através do narcisismo, como fazem os pós-freudianos. Ele não menciona nada acerca da fragilidade narcisico-identificatória, nem acerca da alteração da imagem do corpo - temas que estavam no centro das discussões sobre a anorexia. Segundo Cosenza (2014), em primeiro lugar, Lacan escolhe situar o problema da anorexia além do imaginário, ao invés de colocá-lo como um defeito na estruturação da identidade subjetiva, no estádio do espelho, ele situa o situa na dialética do desejo entre o sujeito e o Outro. A estruturação narcísico-imaginária do sujeito só pode ser compreendida à luz da sua relação com o Outro e com o gozo. Assim, se o narcisismo nos permite compreender a aproximação proposta por Freud entre anorexia e melancolia e consequentemente discutir o paradigma histérico da anorexia, essa dimensão imaginária só é pertinente quando abordada a partir da relação com o Outro e com o gozo. Para nos orientarmos no campo do imaginário sem cairmos na armadilha, é preciso encontrar um ponto de apoio fora, no campo simbólico. Em segundo lugar, Lacan situa no centro da questão anoréxica o problema do laço familiar, sem articulá-lo a relação especular precoce da criança com a mãe. Ele o faz a partir da relação do sujeito ao 
Outro, do qual os pais e, particularmente, a mãe são as primeiras encarnações. Através da anorexia, o sujeito se dirige ao Outro parental para interrogar acerca do seu desejo e do dom de amor. Em terceiro lugar, Lacan aborda a anorexia como questão pulsional, no Seminário XI (Lacan, 1964/1998), rediscutindo a temática clássica da oralidade. Ele chama o objeto em questão de objeto nada (Marcos, 2014).

Se pensamos que o conceito de narcisismo nos permite entender a ligação proposta por Freud (1895/1989) entre anorexia e melancolia, o fazemos a partir de três pontos: a perturbação da identificação narcísica, a introdução de uma instância crítica que se diferencia do eu e se volta sadicamente contra ele e a identificação do eu com o objeto. Entretanto, isto não significa reduzir o problema da anorexia a uma fragilidade narcísico-imaginária. A dimensão imaginária só pode ser abordada a partir da sua relação com o Outro e com o gozo. Quando Lacan não reduz a questão anórexica à problemática narcísico-imaginária, devemos entender que o corpo imaginário não é unicamente a imagem especular, uma representação imaginária tomada como forma total, mas diz respeito também à experiência de ter um corpo como unidade na qual se localiza uma satisfação pulsional, uma experiência de gozo. Lacan (1949/1966) o descreve no estádio do espelho. Esta experiência de gozo no corpo tomado como unidade é acompanhada de uma "azáfama jubilatória", ou seja, a assunção da imagem especular para este ser mergulhado na impotência motora é acompanhada de júbilo.

Para Lacan, a imagem não se reduz a uma gestalt, ela adquire também no registro do simbólico da linguagem uma função significante. Não há imagem unitária possível antes da constituição do corpo como unidade a partir de uma experiência sempre ancorada no registro simbólico como experiência de linguagem. Bassols (2016) afirma que o real de lalíngua dá corpo à imagem que a partir daí constitui o mundo segundo o modelo da unidade do corpo. Temos assim o enlaçamento dos três registros: "o Real de lalíngua faz entrar as representações do simbólico, do significante como substância gozante, no imaginário da unidade corporal" (Bassols, 2016).

As elaborações freudianas sobre o narcisismo e a identificação conceitos necessários à nossa construção - permitem a Lacan o desenvolvimento do estádio do espelho. Para Lacan (1949/1966), a função do estádio do espelho é estabelecer uma relação entre o organismo e a realidade. Para dizê-lo de forma resumida, o estádio do espelho diz respeito a um momento na primeira infância, onde a imagem do corpo ainda não é unificada e, portanto, não captou o gozo caótico do corpo despedaçado. Neste momento, há um investimento libidinal que se fixa na imagem. Para Drummond (2015), tal como na vida animal, o corpo é introduzido na economia de gozo pela imagem do corpo de outros. 
Para que a libido se fixe na imagem do corpo próprio é necessário, contudo, uma perda que possibilite que o gozo seja capturado pela imagem a partir da identificação. Nesta operação, o olhar do outro é fundamental para sustentar esta imagem plana, projetada, e principalmente organizada. O estádio do espelho é um véu para o corpo fragmentado. Para Brousse (2015), o que permite ao sujeito se identificar com esta imagem no espelho é a fala do Outro.

O narcisismo nos permite compreender, até certo ponto, a aproximação entre anorexia e melancolia, entretanto não esgota a questão daquilo que está em jogo na relação da anoréxica com o corpo. Lacan (1974), em A Terceira, afirma que há algo no corpo que excede a dimensão imaginária: ali onde se põe em jogo como vivente, é o que resta da operação significante que mata a Coisa. Aí, o corpo é o apoio do percurso pulsional, no qual a pulsão encontra as bordas que permitem a satisfação. Dafunchio (2001) afirma que “devido a essas bordas, o corpo não é apenas uma superfície imaginária, mas, também, adquire um peso e uma consistência que a anoréxica pretende apagar, como se quisesse se satisfazer da pulsão tão somente no plano imaginário" (p. 39). Segundo a autora, a contrapartida dessa ambição anoréxica é o retorno do excesso rechaçado na deformação da imagem especular.

Nos casos de anorexia, o sujeito está sempre em desacordo com seu corpo, que nunca atinge a forma desejada apesar das restrições alimentares, jejuns, vômitos, diuréticos e laxantes. O sujeito tenta moldar seu corpo, através destas práticas, a uma imagem ideal jamais alcançada. Para Joana, o corpo depende de uma imagem, plana, no espelho, para se identificar. No entanto, ao que parece, esta imagem não sustenta a crença de se ter um corpo. Para Lacan (1975-1976/2005), o ego a2 tem como suporte uma imagem e a imagem que Joana carrega é uma imagem vazia, i( ).

O caso de Joana nos permite ir além de um paradigma histérico da anorexia e interrogar se a anorexia pode ser considerada uma forma de suplência a3 na melancolia. Podemos assim pensar que a identificação clássica anorexia=histeria não encerra a questão. Frequentemente a anorexia tem uma função particular no interior do caso, constituindo-se como uma solução para ao sujeito tal como nos ensinam autores como Dafunchio (2008b) e Schejtman (2013). Nestes casos, a identificação anoréxica impede o desencadeamento da psicose e o sujeito se estabiliza através de uma identificação ao sintoma. Muito fragilizada clinicamente, a recusa de Joana em se alimentar coloca todos no Hospital apreensivos e angustiados. Entretanto, dela ouvimos: "Não tenho nada. Isto é um estilo de vida". "Isto é um estilo de vida" adquire um estatuto holofrásico no seu dizer: não se dialetiza, não se articula a nada. Tais falas nos permitem pensar que, para ela, a anorexia se apresenta como um efeito da melancolia, onde o falasser, sem o recurso de uma 
identificação permeada pelo simbólico, pela fala do Outro, grampeia imaginário e real. Em Joana, como podemos perceber nos casos de melancolia, o real parece destruir o imaginário e engolir a imagem narcísica. A identificação ao "sou anoréxica" funciona como uma suplência imaginária à foraclusão do Nome-do-Pai. Joana nos mostra um enlaçamento deste tipo: uma falha no narcisismo que não permite a construção de uma consistência corporal, aliado a uma extrema pobreza do discurso, as lacunas nas lembranças parecem revelar um lapso do simbólico que, em seu caso, tem como consequência uma irrupção do real no imaginário. Assim, a anorexia, em Joana, funciona como um modo de enlace subjetivo, enodando imaginário, simbólico e real.

Para Dafunchio (2001), se a histérica sabe se servir do significante fálico e o corpo se apresenta como falicizado na mascarada, na anorexia haveria uma recusa do semblante. A autora irá demonstrar a aspiração anoréxica de existir como pura imagem. Joana parece buscar fazer-se um corpo com o estilo de vida anoréxico, a imagem, os croquis desenhados, o interesse pela moda, as roupas, a maquiagem são artifícios que buscam transformar esse corpo em pura imagem, desencarnado. A ingestão de detergente, shampoo, sabonete atesta a tentativa de limpar o corpo de toda e qualquer impureza, do seu excesso de carne. Seriam estes momentos em J oana manifestações maníacas nas quais é o imaginário que destrói o real? Na mania, segundo Dafunchio (2008b), o avanço do imaginário sobre o real produz uma redução do sujeito a uma pura imagem. A anorexia seria, para Joana, um modo de se apropriar do seu corpo, de construir para si uma certa consistência corporal.

O desencadeamento da "tristeza" de Joana, aos 14 anos, nos leva a interrogar a função da irrupção de um gozo no corpo provocado pelas manifestações da feminilidade corporal da adolescência. Dafunchio (2008a) ressalta que, em casos de melancolia, o sujeito se mantém mais ou menos bem durante a infância, onde o corpo se mantém com certa uniformidade, uma sorte de boa forma permitindo um fechamento narcísico que garantiria sua estabilização. Com as mudanças corporais, o advento das curvas e ocos, algo vai exceder a imagem plana, especular, e o corpo vai exigir um novo tratamento de gozo.

Não raro este tratamento passa pelos transtornos alimentares, transtornos que colocam em relevo a questão da imagem do corpo e a relação com o outro. Aprendemos também isto no caso de Joana, para quem é necessário manter um corpo infantil, ou seja, sem os relevos/impasses do feminino, e um "mundo infantil". Este "mundo infantil" aliado ao "estilo de vida" que ela desenha, e agora discute com sua analista, permitem que Joana se coloque em uma relação afetiva com um homem. Neste encontro, Joana extrai um valor fálico para seu corpo objetificado e um tratamento para a feminilidade. A 
imagem vazia i( ), ganha um contorno pela anorexia destituindo os excessos, o informe colocado pelo feminino, o que concede a Joana um corpo para amar. Sem ele, sem este véu de imagem criado por Joana, os fenômenos do corpo despedaçado ameaçam a integridade de sua vida psíquica.

Podemos ainda extrair do caso Joana um saber sobre a saída da melancolia e, consequentemente, sobre a direção do tratamento nestes casos. Sabemos que, na clínica da psicose, o sujeito não conta com a amarração do Nome do Pai, amarração que garante certa estabilidade entre os registros real, imaginário e simbólico. Nestes casos, não haverá uma saída universal, cada um inventará a sua. No entanto, como propõe Miller (2012), nos sujeitos melancólicos, há uma forma a partir da qual o sujeito inventa.

$\mathrm{Na}$ melancolia, o que se observa na clínica, é que há uma superidentificação do sujeito com os papéis sociais (Miller, 2012). A superidentificação é diferente de uma identificação simbólica que, como vimos, é impossível para o melancólico. Bem entendido, a superidentificação ao papel social vem suplenciar o vazio da imagem, i( ). Para isto, é necessária a captura de uma série de traços e uma "identificação com o ser literal do traço significante e não com sua função" (Miller, 2012, p.48). Estes traços são normativos, não podem ser dialetizados, tampouco entrar em conflito, pois a perda deste véu imaginário que assim se propõe volta a desencadear o processo melancólico. Como propôs Miller, este véu é a realização de uma identidade, onde o sujeito equivale aos seus traços. Esta é uma suplência que se faz na junção do imaginário com real.

Vale acrescentar, que os traços capturados neste artifício são uma "coleção de sentenças do supereu" (Miller, 2012, p. 47). O risco de se abalar o imaginário carrega, na melancolia estabilizada, uma descompensação capaz de transbordar, no real, esta coleção relativa ao supereu. No caso de Joana, foi interessante observar que, na adolescência, a mãe dizia coisas como: "para ser bonita é preciso ser magra". I mperativo superegóico que funciona como traço para uma superidentificação que, no entanto, não pode ser abalada. A estabilização de Joana não depende de um processo simbólico, ela passa por uma reconstrução desta cobertura imaginária, na falha do narcisismo, capaz de mascarar seu ser de objeto.

\section{Referências}

Bassols, M. (2016) Corpo da imagem e corpo falante. Retrieved from https://www.congressoamp2016.com/uploads/53c2488eebb84 9ba919a5646a3a0e5028cdd0791.pdf

Brousse, M-H. (2015). Corpos lacanianos: novidades contemporâneas sobre o estádio do espelho. Revista Curinga, 40, 257-271. 
Cosenza, D. (2014). Le refus dans l'anorexie. Rennes: Presses Universitaires de Rennes.

Dafunchio, N. S. (2001). O corpo na anorexia: da imagem ao emblante. Revista Correio, 35, 38-42.

Dafunchio, N. S. (2008a). Las transformaciones del síntoma en anorexias y bulimias. Revista de la Cátedra II de Psicopatologia Universidad de Buenos Aires, 2, 125-140.

Dafunchio, N. S. (2008b). Confines de las psicosis. Buenos Aires: Ed. Serie del bucle.

Drummond, C. (2015). Olhar de mãe. Revista Curinga, 40, 93-101.

Freud, S. (1895/1989). Rascunho G. In J. Salomão (Ed.), Edição Standard brasileira das Obras Psicológicas Completas de Sigmund Freud (Vol. I, pp. 246-256). Rio de Janeiro: Imago.

Freud, S. (1905a/1989). Três ensaios sobre a sexualidade. In J. Salomão (Ed.), Edição Standard brasileira das Obras Psicológicas Completas de Sigmund Freud (Vol. VII, pp. 119233). Rio de Janeiro: I mago.

Freud, S. (1910/1989). Leonardo da Vinci e uma lembrança da sua infância. In J. Salomão (Ed.), Edição Standard brasileira das Obras Psicológicas Completas de Sigmund Freud (Vol. XI, pp. 67-143). Rio de Janeiro: I mago.

Freud, S. (1911/1989). Notas psicanalíticas sobre um relato autobiográfico de um caso de paranóia. In J. Salomão (Ed.), Edição Standard brasileira das Obras Psicológicas Completas de Sigmund Freud (Vol. XII, pp. 15-92). Rio de Janeiro: I mago.

Freud, S. (1913/1989). Totem e tabu. In J. Salomão (Ed.), Edição Standard brasileira das Obras Psicológicas Completas de Sigmund Freud (Vol. XIII, pp. 13-169). Rio de Janeiro: I mago.

Freud, S. (1913a/1989). O interesse científico da psicanálise. In J. Salomão (Ed.), Edição Standard brasileira das Obras Psicológicas Completas de Sigmund Freud (Vol. XIII, pp. 169213). Rio de Janeiro: I mago.

Freud, S. (1914/2004). À guisa de Introdução ao Narcisismo. In Author, Escritos sobre a Psicologia do Inconsciente (Vol 1., pp. 95-131). Rio de Janeiro: I mago.

Freud, S. (1915/2004). Pulsões e destinos da pulsão. In Author, Escritos sobre a Psicologia do Inconsciente (Vol. 1, pp. 133173). Rio de Janeiro: I mago.

Freud, S. (1915/1989). Os instintos e suas vicissitudes. In Author, Edição Standard Brasileira das Obras Psicológicas Completas de Sigmund Freud (Vol. XIV, pp. 117-147). Rio de Janeiro: Imago.

Freud, S. (1917/1989). Luto e Melancolia. In J. Salomão (Ed.), Edição Standard brasileira das Obras Psicológicas Completas de Sigmund Freud, (Vol. XIV, pp. 245-271). Rio de Janeiro: I mago. 
Freud, S. (1923/1981). Le moi et le ça. In Author, Essais de psychanalyse (pp. 219-275).

Freud, S. (1930/1989). O mal estar na civilização. In J. Salomão (Ed.), Edição Standard brasileira das Obras Psicológicas Completas de Sigmund Freud (Vol. XXI, pp. 67-151). Rio de Janeiro: I mago.

Hout, H. (1991). Do sujeito à imagem. São Paulo: Escuta.

Lacan, J. (1949/1966) Le stade du miroir comme formateur dela fonction du 'je'. In Author, Écrits (pp. 93-100). Paris: Seuil.

Lacan, J. (1964/1998). O seminário, livro 11: Os quatro conceitos fundamentais da psicanálise. Rio de Janeiro: Jorge Zahar Ed.

Lacan, J. (1974/2003). Televisão. In Author, Outros Escritos (pp. 508-543). Rio de Janeiro: Jorge Zahar Ed.

Lacan, J. (1974). La troisième. Intervention au congrès de Rome. Retrieved from http://espace.freud.pagespersoorange.fr/topos/psycha/psysem/troisiem.htm.

Lacan, J. (1975-1976/2005). O Seminário, livro 23: O sinthome. Rio de J aneiro: Jorge Zahar Ed.

Marcos, C. M. (2007) Figuras da maternidade em Clarice Lispector ou a maternidade para além do falo. Revista Ágora, X(1), p. 3547. Rio de Janeiro.

Marcos, C. M. (2014). O objeto na anorexia: da falta do objeto ao objeto nada. Estudos e Pesquisa em Psicologia, 14, 987-1004.

Miller, J-A. (2012). A psicose ordinária. Belo Horizonte: Scriptum Livros.

Schejtman, F. (2013). Ensayos de clinica psicoanalítica nodal. Buenos Aires: Grama Ediciones.

\section{Endereço para correspondência \\ Cristina Moreira Marcos}

Pontifícia Universidade Católica - PUC-Minas

Av. I taú, 525, Dom Cabral, CEP 30535-012, Belo Horizonte - MG, Brasil

Endereço eletrônico: cristinammarcos@gmail.com

\section{Renata Damiano Riguini}

Pontifícia Universidade Católica - PUC-Minas

Av. Itaú, 525, Dom Cabral, CEP 30535-012, Belo Horizonte - MG, Brasil

Endereço eletrônico: rriguini@gmail.com

Recebido em: 20/05/2016

Aceito em: 27/04/2017

\section{Notas}

* Psicanalista, Docente do Programa de Pós-Graduação em Psicologia de PUCMinas, Doutora em Psicanálise pela Universidade de Paris 7.

** Pós-Doutoranda em Psicologia no Programa de Pós-graduação em Psicologia da PUC-Minas. Mestre em Teoria Psicanalítica pela Universidade Federal de Minas Gerais, Doutora em Psicologia pela PUC-Minas. 
${ }^{1}$ Este caso integra os casos clínicos discutidos no escopo da pesquisa "Anorexia e Sexuação Feminina", realizada com o apoio da Fundação de Amparo à Pesquisa/FAPEMIG e do Pró-Reitoria de Pesquisa e Pós-Graduação da PUC-Minas (Programa de Incentivo à Pesquisa).

2 Lacan, no Seminário 23, chama de "ego" o que anteriormente designava como o "moi" do imaginário narcisista. Neste seminário, Lacan destaca uma função do ego ao estudar o caso Joyce, e este ego é narcísco, pois há algo que sustenta o corpo como imagem.

${ }^{3}$ Freud não emprega o termo "suplência", é Lacan que o utiliza com o sentido de uma solução subjetiva para os sujeitos psicóticos, atribuindo-lhe uma importante função. Articulada ao imaginário, a suplência apresenta-se a partir de identificações. Sobre este ponto ver: Dafunchio (2008) e Schejtman (2013). Agradecemos a Marconi Martins da Costa Guedes por suas preciosas contribuições nas discussões da pesquisa acerca desta noção.

Este artigo é referido à pesquisa "Anorexia e Sexuação Feminina", realizada com o apoio da Fundação de Amparo à Pesquisa de Minas Gerais/FAPEMIG e da PróReitoria de Pesquisa e Pós-Graduação da PUC Minas e contou também com o apoio de uma bolsa de Pós-Doutorado da Capes.

Este artigo de revista Estudos e Pesquisas em Psicologia é licenciado sob uma Licença Creative Commons Atribuição-Não Comercial 3.0 Não Adaptada. 